\title{
Recent Advances of Nano technology in Bio Medical \& Energy Sector- A Review
}

\author{
Dr.Shubhadra Rajpoot ${ }^{1}$ | Devang Pratap Singh $^{2}$ | Prakarsh Kaushik ${ }^{2}$ \\ ${ }^{1}$ Depart. Of Applied Sciences, Amity School of Engineering and Technology, Greater Noida, India. \\ ${ }^{2}$ Student of Computer Science and Engineering, Amity School of Engineering and Technology, Greater Noida, India.
}

\section{To Cite this Article}

Dr.Shubhadra Rajpoot, Devang Pratap Singh and Prakarsh Kaushik, "Recent Advances of Nano technology in Bio Medical \& Energy Sector- A Review", International Journal for Modern Trends in Science and Technology, Vol. 07, Issue 01, January 2021, pp.- 102-106.

\section{Article Info}

Received on 18-December-2020, Revised on 02-January-2021, Accepted on 08-January-2021, Published on 13-January-2021.

\section{ABSTRACT}

Nanotechnology makes a significant contribution to developing, even revolutionizing many service industries of science and technology like information technology, energy, environmental science, medicine, homeland security, food protection, and transportation, among others. Today's modern nanotechnology integrates current developments in chemistry, physics, materials engineering, and bioengineering to produce new products with specific qualities because their structures are determined on a nano-meter size. This review describes the diverse nano developments of recent years .

KEYWORDS-Nano-Technology, Science, Materials Engineering, Physics, Bio-Engineering

\section{INTRODUCTION}

There's been significant research advancement in the field of evolving nano technology through the use of nano particles as vectors for small and large molecules for the last decades. Broad polymers are being used in nano - particles production. This review presents the most important nanotechnology developments. The word 'Nano' is derived from a Latin word, meaning 'dwarf.' Nano size refers to 1,000 millionth of a particular unit, so the nano-meter is 1,000 millionth of a meter (i.e. $1 \mathrm{n}=109 \mathrm{~m})$. Nanotechnology has become the most popular term in the fields of science such as electronics, physics and engineering for many years. That being said, pharmaceutical and biomedical domains are still to be pursued. Nanotechnology is an emerging field, an integration of basic sciences and applied fields of study such as biophysics, molecular biology and bioengineering. Reduction in size is a basic unit operation with an essential pharmacy implementation. Key benefit of nano-sizing usually involves 1 . Increase surface area 2 . Increase in absorption 3. Increase the amount of dissolution and oral bio availability 4. Rapid start in given course of action. Less dose required in the pharmacy field. Tending to the related chances, the updated additionally recommends how to oversee expansive improvements in these zones.

As right on time as 1959, Richchard Feynman proposed fabricating gadgets with every particle absolutely positioned. In 1986, Eric Drexler distributed a powerful book, motors of creation, in which he portrayed a portion of the advantages and dangers of such a capacity. On the off chance that particles and gadgets can be fabricated by joining 
singular molecules under PC control, it will be conceivable to construct structures out of diamond,100 times as solid as steel, to manufacture PCs littler than a bacterium, and to manufacture constructing agent and small scale plants of different sizes, equipped for making complex items and even of copying themselves. Drexler's resulting book, nano-frameworks, validated these noteworthy shellfishes, included still more. An independent tabletop manufacturing plant could deliver its copy in 60 minutes. Gadgets with moving parts could be unfathomably proficient. Atomic assembling activities could be completed with disappointment rate short of what one out of a quadrillion (Dinauer N et al., 2005 and Widder K et al., 1979).

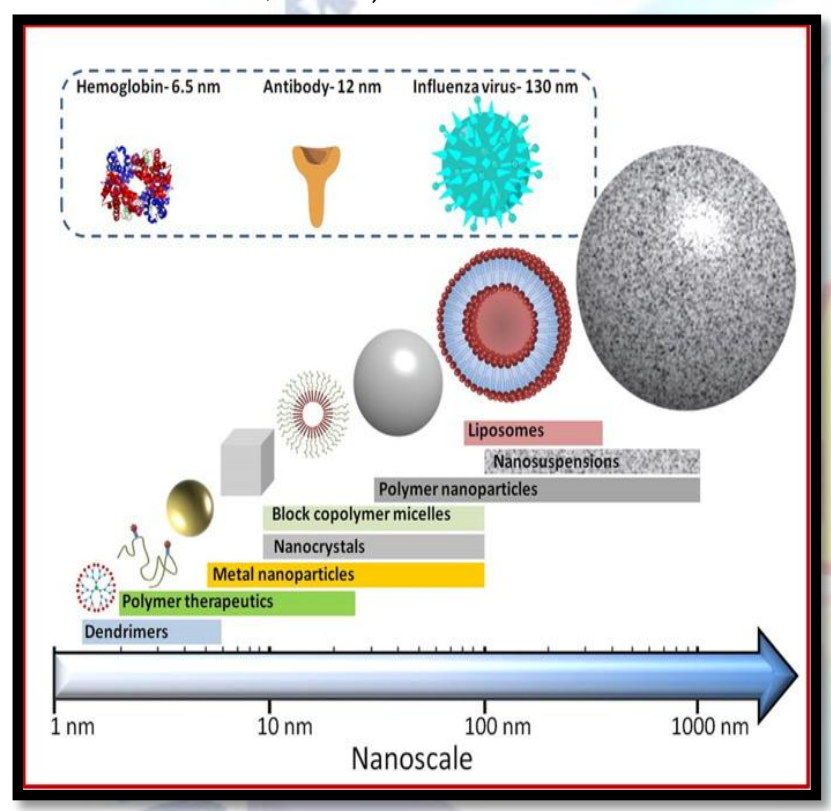

Figure 1: Representing the nano-particles with their approximate sizes

It appears to be certain that whenever progressed nanotechnology is ever evolved, its items will be amazingly ground-breaking. When sub-atomic assembling was proposed, dangers related with it started to be distinguished. Motors of creation portrayed one risk currently viewed as improbable, yet at the same time conceivable dim goo. A little nano-machine fit for replication could in principle duplicate itself too often. On the off chance that it were fit for enduring outside, and of utilizing biomass as crude material it could seriously harm the earth.

\section{FOUR GENERATIONS}

Mihail (Mike) Roco of the U.S. Public Nanotechnology Initiative has portrayed four ages of nanotechnology improvement (see outline underneath). The current time, as Roco portrays it, is that of latent nanostructures, materials intended to perform one errand. The subsequent stage, which we are simply entering, presents dynamic nanostructures for performing multiple tasks; for instance, actuators, medicate conveyance gadgets, and sensors. The third era is relied upon to start rising around 2010 and will highlight nano-frameworks with a large number of communicating segments. A couple of years from that point forward, the main coordinated nano-frameworks, working (as indicated by Roco) much like a mammalian cell with rogressive frameworks inside frameworks, are relied upon to be created.

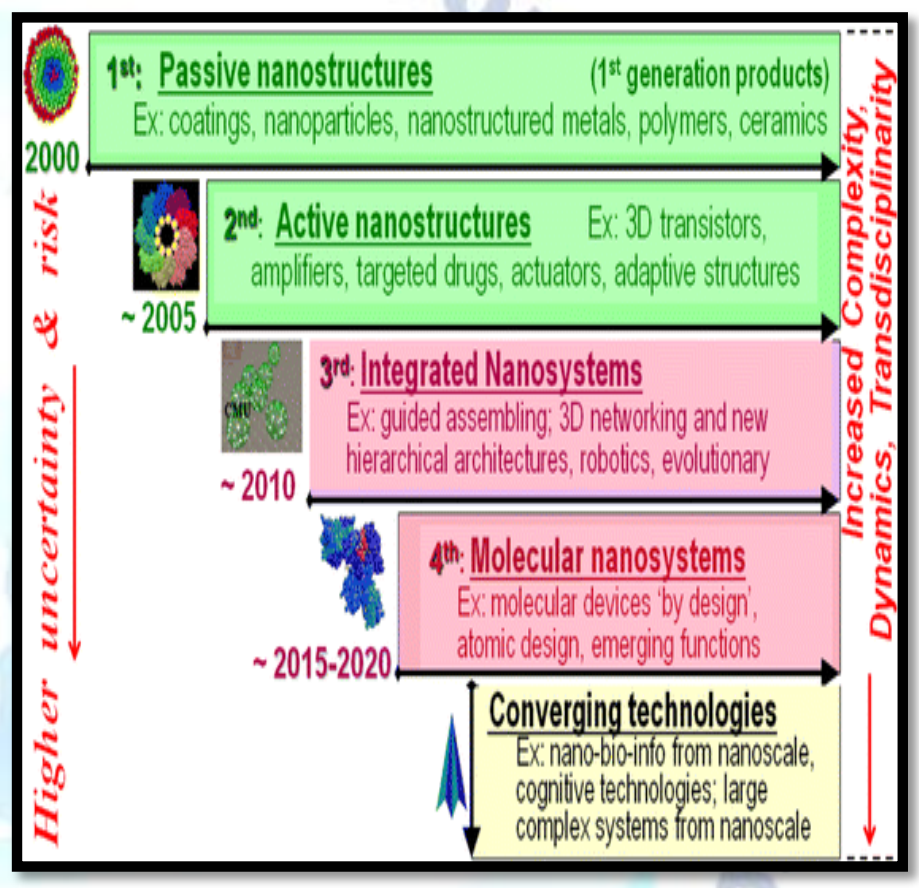

Figure 2: Representing the four generations of nanoparticles.

Nanotechnology has significantly added to significant advances in registering and gadgets, prompting quicker, littler, and more versatile frameworks that can oversee and store bigger and bigger measures of data. These consistently advancing applications include:

-Transistors, the essential switches that empower all cutting edge figuring, have gotten littler and littler through nanotechnology. When the new century rolled over, a commonplace semiconductor was 130 to 250 nanometers in size. In 2014, Intel made a 14 nanometer semiconductor, at that point IBM made the initial seven nanometer semiconductor in 2015, and afterward Lawrence Berkeley National Lab showed a one nanometer semiconductor in 2016! Littler, quicker, and better semiconductors may imply that soon your PC's 
whole memory might be put away on a solitary small chip.

-Ultra-top notch showcases and TVs are presently being sold that utilization quantum specks to create more lively hues while being more vitality effective.

-Nanoparticle copper suspensions have been created as a more secure, less expensive, and more

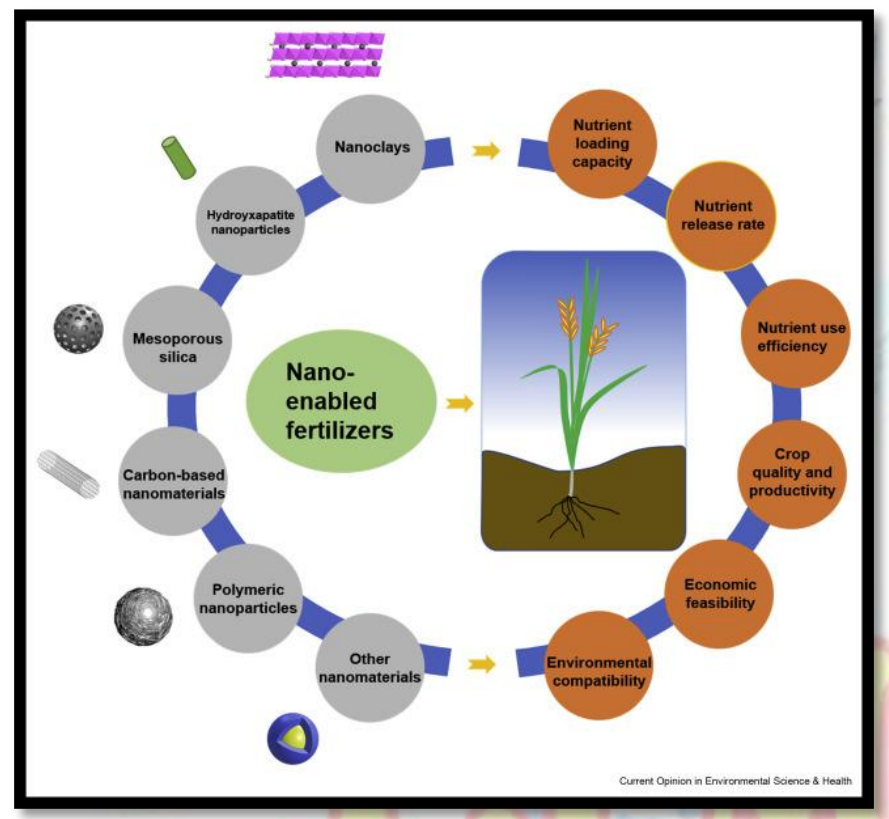

dependable choice to toxic weld and different dangerous materials normally used to meld hardware in the gathering cycle.

\section{USE OF NANOTECHNOLOGY IN AGRICULTURE AND FOOD PRODUCTION}

The world's total population is almost 7.5 billion, with more than 50 per cent located in Asia. A significant proportion of all those living in developing countries constantly face shortages of food due to environmental changes or political turmoil, although there is a food surplus in the developed countries. Drought and pest-resistant crops, which also increase yields, are an opportunity for developing countries. In developing countries, the food industry is powered by consumer demands for fresher and nutritious options. This is a major business, for instance, the food industry in the United Kingdom is thriving with an annual growth rate of $6.2 \%$ and demand for fresh food has risen by $12 \%$ in the last few years. The ability of nanotechnology to transform medical services, textiles, Substances, Information and communication systems and the electricity market are very well-publicised. In reality, some nanotechnology-enabled items are already available in the markets, such as antibacterial dressings, translucent sunscreen lotions, stain-resistant fabric, scratch-free automotive paint and self-cleaning screens. The United States Department of Agriculture 's road-map released in September 2003 discussed the adaptation of nanotechnology to both the agricultural and food industries. The hypothesis is that nanotechnology will change the food industry as a whole, affecting the way food is produced, processed, packaged, transported and consumed.

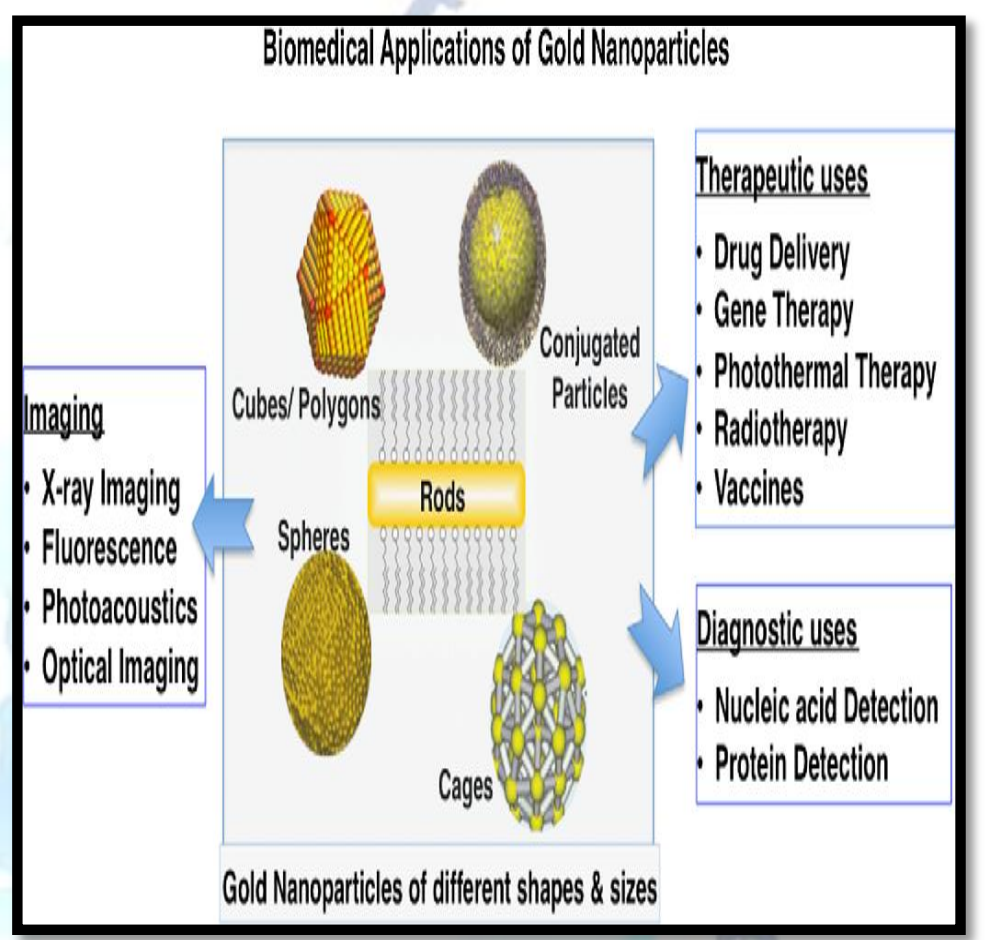

\section{ENERGY APPLICATIONS}

- Nanotechnology is improving the efficiency of fuel production from raw petroleum materials through better catalysis. It is also enabling reduced fuel consumption in vehicles and power plants through higher-efficiency combustion and decreased friction.

- Researchers are developing wires containing carbon nanotubes that will have much lower resistance than the high-tension wires currently used in the electric grid, thus reducing transmission power loss.

- Nanotechnology is already being used to develop many new kinds of batteries that are quicker-charging, more efficient, lighter weight, have a higher power density, and hold electrical charge longer. 
MEDICINE: Researchers are developing customized nanoparticles the size of molecules that can deliver drugs directly to diseased cells in your body. When it's perfected, this method should greatly reduce the damage treatment such as chemotherapy does to a patient's healthy cells.

FOOD: Nanotechnology is having an impact on several aspects of food science, from how food is grown to how it is packaged. Companies are developing nanomaterials that will make a difference not only in the taste of food, but also in food safety, and the health benefits that food delivers.

FUEL CELLS: Nanotechnology is being used to reduce the cost of catalysts used in fuel cells to produce hydrogen ions from fuel such as methanol and to improve the efficiency of membranes used in fuel cells to separate hydrogen ions from other gases such as oxygen.

BETTER AIR QUALTY: Nanotechnology can improve the performance of catalysts used to transform vapors escaping from cars or industrial plants into harmless gasses. That's because catalysts made from nanoparticles have a greater surface area to interact with the reacting chemicals than catalysts made from larger particles. The larger surface area allows more chemicals to interact with the catalyst simultaneously, which makes the catalyst more effective.

CHEMICAL SENSORS: Nanotechnology can enable sensors to detect very small amounts of chemical vapors. Various types of detecting elements, such as carbon nanotubes, zinc oxide nanowires or palladium nanoparticles can be used in nanotechnology-based sensors. Because of the small size of nanotubes, nanowires, or nanoparticles, a few gas molecules are sufficient to change the electrical properties of the sensing elements.

FABRIC: Making composite fabric with nano-sized particles or fibers allows improvement of fabric properties without a significant increase in weight, thickness, or stiffness as might have been the case with previously-used techniques.

SOLAR CELLS: Companies have developed nanotech solar cells that can be manufactured at significantly lower cost than conventional solar cells.
BATTERY: Companies are currently developing batteries using nanomaterials. One such battery will be a good as new after sitting on the shelf for decades. Another battery can be recharged significantly faster than conventional batteries.

This brief study will describe critical features of these transitions illustrating current research in the agricultural food industry and what potential impacts it could have. Nanotechnology has the ability to change the food and agriculture industry with new technologies for molecular disease control, rapid detection of diseases, enhanced ability of plants to absorb nutrients, etc. Advanced sensors and smart delivery systems can help. The agricultural industry is battling viruses and other crop infections. Nanostructured catalysts will be available very soon to increase the effectiveness of pesticides and herbicides, enabling smaller concentrations to be used. Nanotechnology can also partially protect the environment by the use of sustainable energy sources and membranes or catalysts to reduce carbon emissions and clean up existing contaminants. The agricultural technique commonly used throughout the United States of America, Europe and Japan, that makes efficient use of modern crop management technology, is called Controlled Environment Agriculture (CEA). CEA is a very sophisticated intensive method of hydroponic-based agriculture. Crops are cultivated in a regulated environment such that horticultural activities can be optimized.

\section{CONCLUSION}

Based on the data analysis from this study, Nanotechnology has the ability to be the gateway to a different era in the fields of food and agriculture, building materials, mechanical engineering, pharmacy and electrical engineering. Even though reproduction of natural systems is one of the most promising fields of this development, scientists have been trying to understand its remarkable complexity. In addition, nanotechnology and nanomaterials are a rapidly expanding field of study where new developments of nano-scale materials can be used for the gain of industry, and there are a range of capable inventions that could theoretically alter the total strength and life-cycle costs of infrastructure projects to build a new environment to make a new universe in the upcoming years. 


\section{REFERENCES}

[1] Chaturvedi S, and Dave PN (2014). Emerging applications of nanoscience. Paper presented at the Materials Science Forum, 152-159

[2] Najim M, Modi G, Mishra YK, Adelung R, Singh D, Agarwala V. (2015). Ultra-wide bandwidth with enhanced microwave absorption of electroless Ni-P coated tetrapod-shaped $\mathrm{ZnO}$ nano-and microstructures. Physical Chemistry Chemical Physics, 17(35): 2923-2933

[3] Dr. Subhadra Rajpoot, "A Review on ways to Manage Biomedical Waste at Different Locations in Faizabad", International Journal for Modern Trends in Science and Technology, Vol. 06, Issue 01, January 2020, pp.-33-36..

[4] Maine E, Thomas V, Bliemel M, Murira A, Utterback J. (2014). The emergence of the nanobiotechnology industry. Nature nanotechnology, 9(1): 12-15.

[5] Pratsinis SE. (2016). Overview-Nanoparticulate Dry (Flame) Synthesis \& Applications. UNE, 13-15.

[6] Dr. Subhadra Rajpoot and Devang Pratap Singh, "Emerging Public Health Concern and Air Pollution: A Case Study of Delhi's Air Pollution Governance", International Journal for Modern Trends in Science and Technology, Vol. 06, Issue 05, May 2020, pp.: 196-201

[7] Sabet M, Hosseini S, Zamani A, Hosseini Z, Soleimani H. (2016). Application of Nanotechnology for Enhanced Oil Recovery: A Review. Paper presented at the Defect \& Diffusion Forum.

[8] Dr.Subhadra Rajpoot, Kabom Lego, Effect Of Particulate Matter (Pm) On Climate, Plants, Human Health And Ecosystem, International Journal Of Scientific Research : Volume-7 | Issue-5 | May-2018

[9] Dreher K.L. (2004). Health and environmental impact of nanotechnology: toxicological assessment of manufactured nanoparticles. Toxicological Sciences, vol. 77: pp. 35-39.

[10] Allen T.M, Cullis P.M. (2004). Drug delivery systems: entering the mainstream. Science, 303: 181-188.

[11] Dr.SubhadraRajpoot, Future Trends in Fiber Optics Communication, IJCI Volume 6 April2017

[12] Ahmed S, Ahmad M, Swami B.L, Ikram S. (2016). A review on plants extract mediated synthesis of silver nanoparticles for antimicrobial applications: a green expertise. Journal of Advanced Research, 7(1): 17- 28.

[13] Yetisen A.K, Qu H, Manbachi A, Butt H, Dokmeci M. R, Hinestroza J.P, Yun S.H. (2016). Nanotechnology in Textiles. Acs Nano

[14] Firoozi A.A, Taha M.R, Firoozi A.A. (2014). Nanotechnology in Civil Engineering. EJGE, 19: 4673-4682.

[15] P. Kaushik, D. P. Singh and S. Rajpoot, "Fibre Optic Communication In 21st Century," 2020 International Conference on Intelligent Engineering and Management (ICIEM), London, United Kingdom, 2020, pp. 125-129, doi: 10.1109/ICIEM48762.2020.9160141.

[16] Altairnano. (2014). http://www.altairnano.com applications.html.

[17] Bohn L, Rick A, Myer A. O'Connor G. (2001). Soil Chemistry. Published by. Wiley. Technology \& Engineering. 